\author{
*S. H. WraY, M.B. (Sheffield), M.R.C.P. \\ *R. S. Kocen, M.B. (Leeds), M.R.C.P. \\ K. J. Wright, B.M., B.Ch. (Oxon.) \\ The Department for Nervous Diseases, The Middlesex Hospital, London, W.I.
}

IT HAS been recognised for some years that the tetracycline group of antibiotics can produce a rise in the level of the blood urea-particularly in the presence of renal impairment. (Bateman, Barberio, Grice, Klopp and Pierpont, 1952). Both the clinical and theoretical aspects of this have been recently reviewed by Shils (1962, 1963). He found that tetracycline may produce azotæmia, hyperphosphatæmia and acidosis with increased urinary nitrogen and sodium excretion but with little, if any, rise in the serum creatinine and uric acid levels. These changes are often associated with deterioration in the patient's condition, particularly with increasing anorexia, nausea and vomiting. Both the clinical and metabolic changes are usually seen some days after the commencement of the therapy and the return to normal is also delayed after the administration of the drug has ceased. In patients with suspected chronic renal infection, treatment with one of the tetracyclines may thus produce a deterioration in the clinical and biochemical picture which may then be thought to be due to the advance of the underlying disease producing further renal insufficiency, though the changes can be reversed by the withdrawal of the offending drug. We report here two cases in which tetracycline may have been responsible for such a state.

\section{Case no. 1}

A 54-year-old woman suffering from multiple sclerosis since the age of 16 years, had had a kidney infection during her first pregnancy. She had never been catheterised for the passing of urine. In 1954 on a routine visit to the Neurological Clinic she was found to have albuminuria and a urine S.G. of 1010 . On admission to hospital in February, 1963, she admitted to frequency of micturition for two or three years and polydipsia for one year. Her blood pressure was $190 / 130 \mathrm{~mm}$. $\mathrm{Hg}$.

Investigations:

Hb. $63 \%$; MCHC $35 \%$, normochromic normocytic anæmia; ESR $65 \mathrm{~mm}$./hr. Urine: albumin a trace: WBC +++ no casts. Culture grew $E$. coli and Strep. facalis. Blood urea $146 \mathrm{mg} . / 100 \mathrm{ml}$. Serum electrolytes: normal.

Treatment:

The patient was given Urolucosil (sulphamethizole) $800 \mathrm{mg}$. daily from February 7 th to the 14th;

*Present Address-National Hospital, Queen Square, London, W.C.1.
Furadantin (nitrofurantoin) $400 \mathrm{mg}$. daily from February 15th to the 18th; Myanesin (mephenesin) 2 g. daily from February 9 th to the 22nd; tetracycline $500 \mathrm{mg}$. stat. and $1 \mathrm{~g}$. daily from February 8th to March lst-a period of twenty days. The course of the patient's blood urea is shown in Figure 1. It reached a maximum of $429 \mathrm{mg}$. $/ 100 \mathrm{ml}$. with normal electrolytes, 7 days after the tetracycline was stopped.

There was deterioration in her clinical condition from February 21 st onwards, 13 days after the commencement of the tetracycline; and clinical improvement from March 11 th onwards, 10 days after the cessation of tetracycline. Her urine output appeared satisfactory throughout and her blood pressure was maintained. On discharge from hospital in May, 1963, her blood urea was $95 \mathrm{mg} . / 100 \mathrm{ml}$. and in the Out Patient Clinic in July, 1963 it was 144 $\mathrm{mg} . / 100 \mathrm{ml}$. The albuminuria persisted.

\section{Case no. 2}

A 72-year-old man developed increasing confusion in May, 1963. His blood pressure was $190 / 135 \mathrm{~mm}$ Hg. (previously 170/75). On admission on June 5th 1963 , he had papillodema with widespread retina hæmorrhages and a few exudates, mild left heme paresis and considerable intellectual impairment.

\section{Investigations:}

Hb. $90 \%$; ESR $80 \mathrm{~mm}$./hr. Urine: albumin a trace, WBC + , $\mathrm{RBC}+$, no casts. Culture grew initially $B$. proteus, then $E$. coli and later Staph. pyogenes. Blood urea: $110 \mathrm{mg} .100 \mathrm{ml}$. Serum electrolytes: normal. Serum proteins: a slight increase in gamma globulin. The antinuclear factor was negative.

\section{Treatment:}

The patient was given tetracycline $1 \mathrm{~g}$. daily from June 21 st to the 28 th-a period of 7 days. The course of the patient's blood urea is shown in Figure 2.

There was a steady deterioration in his clinical condition from the day of admission until his death 26 days later on July 2 nd, in spite of an adequate fluid intake and urine output over this period. It was thought that the clinical deterioration and the rising blood urea were a manifestation of the underlying disease process but it was difficult to explain the sudden onset of this phase. The patient continued to deteriorate after the tetracycline was stopped and it is tempting to attribute the sudden rapid rise in the blood urea to the tetracycline therapy. At post mortem he was found to have chronic pyelonephritis, cerebral arteriosclerosis and several small cerebral infarcts.

\section{Discussion}

Following reports of an azotemic effect of tetracycline in certain patients since the initial 


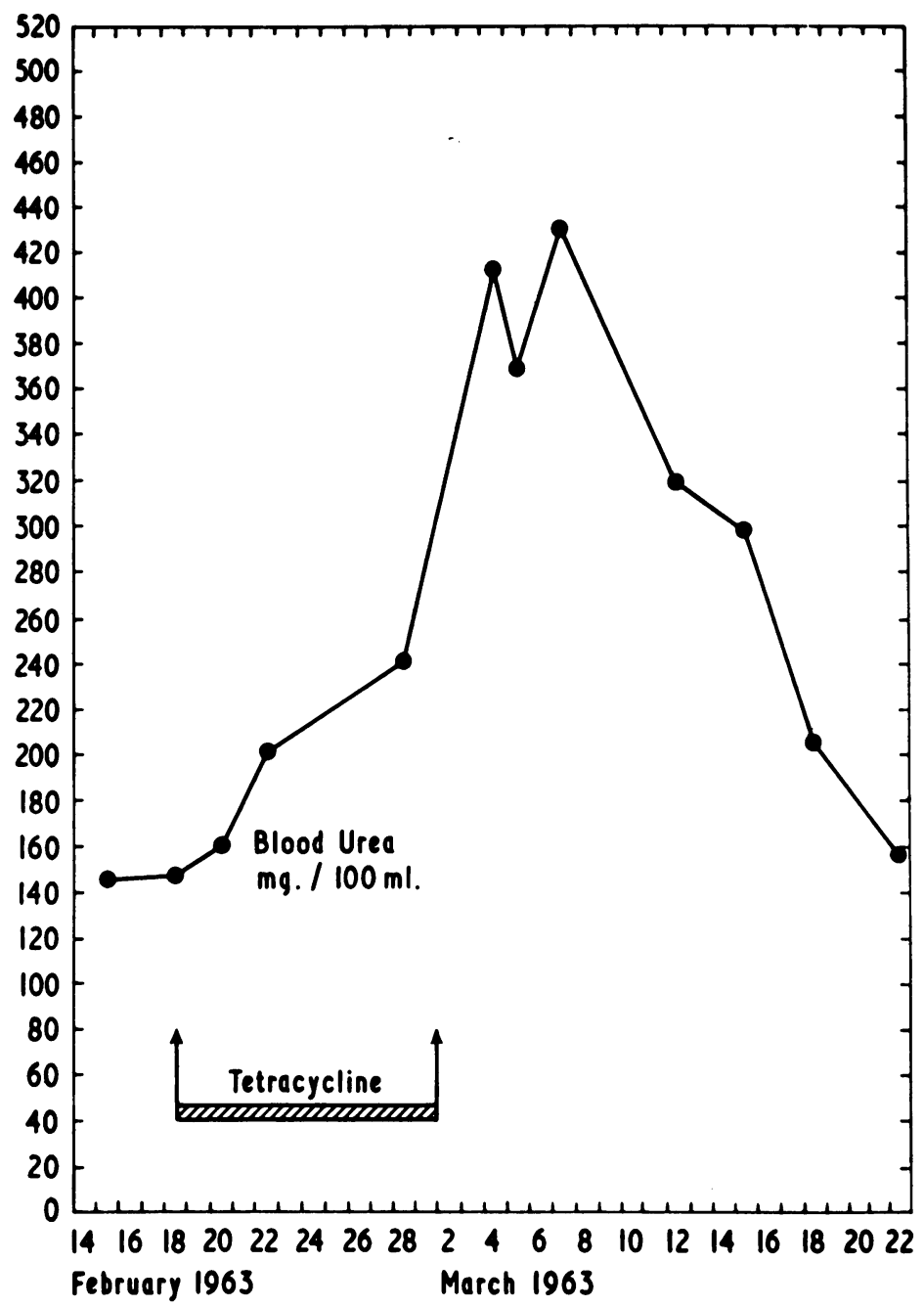

Fig. 1

observation of Bateman and others (1952), Shils (1963) made a study of 15 patients to examine in more detail certain metabolic effects of tetracycline in man in an attempt to delineate their nature more clearly and to assess their clinical significance, especially in patients with renal disease. Of his 15 patients, 8 had blood urea nitrogen levels of less than $20 \mathrm{mg} .{ }^{\prime}$ $100 \mathrm{ml}$. in the pre-tetracycline control period and 7 patients had some obvious form of chronic renal disease. He found that tetracycline levels in patients with renal insufficiency can be up to thirteen times greater than in normals following an equivalent oral dose, and showed that despite generally lower doses of tetracycline given for shorter periods, the patients with renal disease developed much more obvious symptomatic reactions to the drug than did those with adequate kidney function.

It is thought that tetracycline was responsible for the deterioration in Case 1 associated with an underlying renal disease dating back to her first.pregnancy. In Case 2 with proven chronic pyelonephritis the tetracycline therapy aggravated his clinical condition and may have seriously influenced his prognosis. Unfortunately serum creatinine levels were not estimated in these two patients. The failure of the serum creatinine to rise in similar cases of Shils (1963) 


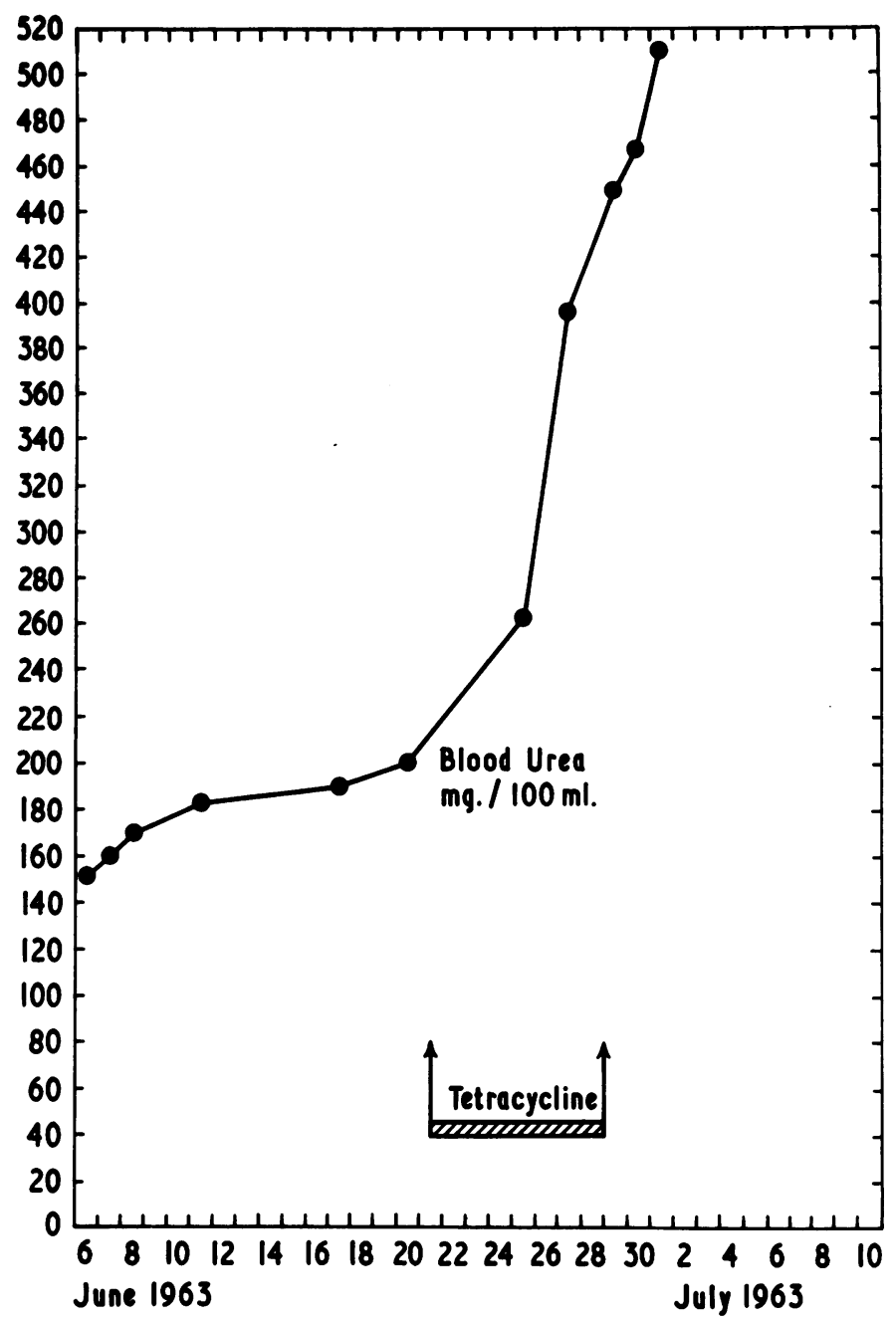

FIG. 2

suggests that the rising blood urea is not due to the effect of the antibiotic directly on the kidney producing further impairment of renal function. Shils $(1962,1963)$ postulates that the rise in the blood and urinary urea nitrogen is the result of impaired protein synthesis due to the action of the tetracycline on various enzyme mechanisms. The clinical importance of this must be emphasised. This mechanism must be suspected whenever patients treated with standard doses of tetracycline show clinical deterioration in the presence of a rapidly rising blood urea. Awareness of the existence of this tetracycline toxicity may produce considerable benefit to the patient.

\section{Summary}

Two cases are reported in which tetracycline toxicity may have produced a rise in the level of blood urea nitrogen in the presence of renal impairment. One patient recovered following cessation of tetracycline therapy.

We thank Professor R. W. Gilliatt for permission to publish Case 1, Dr. M. Kremer for permission to publish Case 2 and the Nursing Staff of Campbell o Thomson Ward for their care and attention to the patients.

\section{REFERENCES}

Bateman, J. C., Barberio, J. R., Grice, P., Klopp, C. T., Pierpont, H. (1952): Fatal Complications of Intensive Antibiotic Therapy in Patients with Neoplastic Disease. Arch. intern. Med., 90, 763. SHILS, M. (1962): Some Metabolic Aspects of Tetracycline. Clin. Pharmacol. Ther., 3, 321.

SHILs, M. (1963): Renal Disease and Metabolic Effects of Tetracycline. Ann. intern. Med., 58, 389. 